\title{
O DESLOCAMENTO DA LEGITIMIDADE DOS TRADUTORES E DOS INTÉRPRETES DE LIBRAS-PORTUGUÊS E O IMAGINÁRIO SOCIODISCURSIVO: PROBLEMATIZANDO O ETHOS
}

\author{
DISPLACEMENT OF PORTUGUESE/BRAZILIAN SIGN LANGUAGE \\ TRANSLATORS/INTERPRETERS LEGITIMACY AND THE SOCIAL DISCURSIVE \\ IMAGINARIES: PROBLEMATIZING THE ETHOS
}

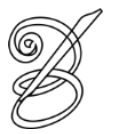 \\ Luiz Cláudio da Silva SOUZA ${ }^{\mathrm{i}}$ \\ Doutorando no Programa Interdisciplinar em Linguística Aplicada (UFRJ) \\ Professor do curso Letras/Libras \\ Universidade Federal de Goiás (UFG) \\ Goiânia, Goiás, Brasil \\ 1.claudio.ufg@gmail.com
}

Resumo: Este artigo tem por objetivo analisar os fatores que impulsionaram a construção de uma nova legitimidade dos Tradutores e dos Intérpretes de Libras-Português - TILSP no Brasil. Nesse sentido, percorre-se inicialmente a vários eventos sociais que são responsáveis pela transição da legitimidade empírico-caritativa para uma nova tida como formativa-profissionalizante. Por último analisaremos os efeitos das duas legitimidades na construção do ethos dos TILSP.

Palavras-chave: Legitimidade. Ethos. TILSP.

Abstract: This paper aims at analyzing the factors that have encouraged the construction of a new Portuguese/Brazilian Sign Language translators/interpreters legitimacy in Brazil. In this sense, numerous social events responsible for the transition from an empirical/charitable legitimacy to a new formative/professionalizing one are covered. At last, we shall analyze the effects of such two legitimacies in the construction of the Portuguese/Brazilian Sign Language translators/interpreters ethos.

Key words: Legitimacy. Ethos. Portuguese/Brazilian Sign Language Translators/Interpreters.

\section{Introdução}

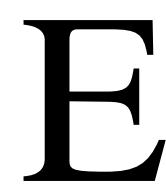

ste trabalho é fruto de pesquisas que tem como foco analisar os imaginários sociodiscursivos que circulam com relação aos Tradutores e aos Intérpretes de Libras-

Português - TILSPii . Os estudos evidenciam que o momento atual tem sido marcado por um deslocamento na legitimidade dos profissionais (SOUZA, 2014). A transição da legitimidade não tem sido destacada como um fator relevante da profissão e, sobretudo, este termo carece de uma definição mais adequada para dar conta do fenômeno que estamos vivenciando.

SOUZA. O deslocamento da legitimidade dos Tradutores e dos Intérpretes de Libras-Português e o imaginário sociodiscursivo: problematizando o ethos

Belas Infiéis, v. 5, n. 1, p. 39-57, 2016. 
De acordo com Charaudeau (2008, p. 65), para ser legitimado, é necessário o reconhecimento de um sujeito por outros sujeitos, o qual é realizado em nome de um valor que é aceito por todos. Nesse sentido, a noção de legitimidade designa o estado ou a qualidade daquela cuja ação é bem fundamentada (CHARAUDEAU, 2008, p. 65). De modo complementar, definimos este conceito como sendo uma forma de reconhecimento de um indivíduo depois de atender determinadas características consideradas relevantes para a comunidade em que se está inscrito.

Desde o início de sua atuação e sobre influência de diversos fatores, os TILSP legitimaram-se no decorrer dos anos. Pode-se dizer que esta legitimidade deslocou-se de uma perspectiva empírico-caritativa para uma legitimidade formativa-profissionalizante representada abaixo:

Figura 1 - Deslocamento da legitimidade

Legitimidade empírico-caritativa $\longrightarrow$ Legitimidade formativa-profissionalizante

Este deslocamento se justifica pelo fato de que a cada momento histórico necessitavase repensar o papel do TILSP, impulsionando uma nova legitimidade. Esta, por sua vez, possibilitava a circulação de imaginários que culminavam em uma nova imagem dos TILSP ou, por assim dizer, fundamentavam um estatuto para a classe. Para elucidar essa questão, vamos explicitar o momento de constituição das duas legitimidades, citadas acima.

A legitimidade empírico-caritativa constituiu-se por volta da década de 1980 (LEITE 2005; QUADROS 2004; ROSA 2005, entre outros). Naquela época, muitos começavam a atuar como intérpretes com base em conhecimentos adquiridos cotidianamente por meio de contato com as pessoas surdas, inclusive nas instituições religiosas. Segundo Santos (2006, p.71), “[...] $\mathrm{Na}$ história dos ILS [intérpretes de língua de sinais], os lugares iniciais para a atuação desse profissional foram às igrejas, as instituições de caridade e os espaços familiares em que transitavam surdos".

O aprendizado, em muitos casos, era motivado em uma perspectiva de "ajudar" ao surdo. Por outro lado, a legitimidade formativa-profissionalizante, segundo a hipótese que levantamos, é um acontecimento recente ainda em transição, motivado por diversos fatores dentre os quais, inicialmente, salientamos a legislação vigente, a formação acadêmica dos 
profissionais e as políticas educacionais dos surdos. Recentemente, podemos observar que alguns aspirantes da profissão buscam formação antes de começar a atuar como intérpretes e/ou procuram certificar-se por meio de exames de proficiência, bem como, outras formas de habilitação que os permitam exercer a profissão. Embora esta seja uma postura mais atual, acaba por demonstrar uma mudança de comportamento que representa um fenômeno em expansão.

O deslocamento da legitimidade tem influenciado diretamente na relação entre TILSP e surdos, sobretudo no que tange ao processo de profissionalização. Hoje em dia, focaliza-se o oferecimento do serviço de tradução ou de interpretação de modo profissional e não mais no sentido de "ajuda" (embora este ainda exista). Isso minimiza, em parte, os atritos que os surdos poderiam ter em relação aos TILSP por conta de uma possível conduta imprópria de pessoas sem formação para exercer a função.

O trajeto percorrido entre a legitimidade empírico-caritativa e a legitimidade formativaprofissionalizante não aconteceu de imediato. Assim sendo, não é possível desconsiderar que as duas legitimidades coexistam ainda hoje. No entanto, a consolidação da profissionalização dos TILSP é inevitável e as posturas que orbitam fora dos padrões de reconhecimento da classe, como aceitáveis para o exercício da profissão, provavelmente, serão rechaçadas pela Comunidade Surda.

A legitimidade formativa-profissionalizante tem impulsionado mudanças significativas na profissão. Os efeitos produzidos, entretanto, nem sempre são livres de tensão. A construção da imagem dos TILSP, também denominada como ethos por Souza (2014), encontra seu momento de instabilidade. Abordaremos esta questão em maiores detalhes, após explicitarmos alguns movimentos observáveis que deslocam a profissão.

\section{Deslocamentos na representatividade política da classe e na habilitação para atuação}

Historicamente, as atividades de tradução e de interpretação de Libras e português começaram de forma empírica. Muitos tradutores e intérpretes adquiriram sua formação com base na experiência construída pelo exercício da atividade no dia-a-dia. No entanto, atualmente, vivemos um momento de deslocamento na construção da imagem dos TILSP. Este fato está ligado a todos os avanços ocorridos até o presente momento.

Recentemente, houve também algumas conquistas na perspectiva da formação acadêmica. Tais avanços consistem no oferecimento de cursos de formação com o intuito de profissionalização em nível de graduação e pós-graduação. Alcançaram-se, ainda, muitos

SOUZA. O deslocamento da legitimidade dos Tradutores e dos Intérpretes de Libras-Português e o imaginário sociodiscursivo: problematizando o ethos

Belas Infiéis, v. 5, n. 1, p. 39-57, 2016. 
outros progressos no que concerne ao reconhecimento do TILSP enquanto profissional. Assim, a certificação de proficiência em tradução e interpretação - Prolibras, e a criação das associações representativas da classe foram iniciativas relevantes.

Vale salientar que as certificações também sofreram deslocamentos. Assim sendo, as titulações que habilitavam os profissionais a atuarem como intérpretes eram basicamente expedidas pelas associações de surdos, principalmente pela FENEIS - Federação Nacional de Educação e Integração do Surdo. Após a aprovação da Libras - Língua Brasileira de Sinais, em 2002, e sua regulamentação, em 2005, vêm a possibilidade de implementar um exame de proficiência de abrangência nacional. Assim surge o Prolibras - Exame Nacional para Certificação de Proficiência no Ensino da Língua Brasileira de Sinais (Libras) e para Certificação de Proficiência na Tradução e Interpretação da Libras-Língua Portuguesa. Nesse sentido, o Prolibras acaba por substituir os exames precedentes que não estavam vinculados a instituições ligadas ao ensino universitário.

Outro movimento observável está no próprio deslocamento que vem acontecendo na troca das organizações representativas da classe dos TILSP. Os profissionais estiveram por

42 muitos anos abrigados nas associações de surdos e, por assim dizer, as conquistas dos surdos geravam reflexos na classe. Na medida em que a classe dos TILSP se torna sólida, seja através das associações de TILSP, seja através de outros modos de representatividade, surge a possibilidade de se contribuir ativamente para os avanços da Comunidade Surda.

\subsection{Deslocamentos na denominação}

No que diz respeito ao deslocamento na denominação, podemos observar que as mudanças na concepção em relação aos surdos e à Libras contribuíram para o deslocamento na concepção da profissão.

Desde o início da atuação profissional, em meados da década de 1980, até a presente conjuntura, podemos dizer que vivemos um momento de deslocamento na construção da imagem dos TILSP.

Neste trabalho optamos em utilizar a sigla TILSP (tradutores e intérpretes de LIBRASPortuguês) colocando-se a Libras e também o português em evidência como par linguístico da tradução e da interpretação. Devido, a inserção acadêmica dos surdos nos espaços de produção de conhecimento como pesquisadores e professores, o fluxo da interpretação tem sido invertido. Desse modo, podemos observar, por exemplo, um crescente número de palestras ministradas

SOUZA. O deslocamento da legitimidade dos Tradutores e dos Intérpretes de Libras-Português e o imaginário sociodiscursivo: problematizando o ethos

Belas Infiéis, v. 5, n. 1, p. 39-57, 2016. 
em Libras por pessoas surdas e ouvintes fluentes nessa língua. Atualmente, em alguns congressos específicos, quem tem tido necessidade de interpretação simultânea são as pessoas que tem pouco ou nenhum domínio de Libras. Isso nos leva a afirmar que os surdos não estão mais na posição somente de "receptores" de conhecimento, todavia, atuam também como produtores e disseminadores deste. Assim sendo, para situar esse momento histórico de ascensão social dos surdos, acreditamos que o mais viável é colocar as duas línguas (Português e Libras) em posição de igualdade, portanto, TILSP. No entanto, esses não são os únicos motivos que nos fizeram marcar essa transição da (des)construção da imagem do profissional. Alguns outros fatores de organização da classe, formação acadêmica, área de atuação e o fluxo de interpretação fizeram com que repensássemos diversas questões em relação à profissão. Todas essas reflexões nos fazem acreditar que necessitamos de mudanças na forma como visualizamos este profissional. Para repensar as diversas questões que envolvem o TILSP é necessário ressignificar esse profissional de acordo com todos os fatores que envolvem sua atuação. Assim sendo, aproveitaremos a próxima subseção para aprofundar um pouco mais as questões relacionadas à formação.

\subsection{Deslocamentos na formação}

É notório que a busca por formação qualificada pelos TILSP tem gerado diferentes modos de organização e legitimação profissional. A prova disso está na conscientização da classe, na luta por melhorias no exercício da atividade de tradução e de interpretação. Essa militância culminou na aprovação da Lei 12.319 de $1^{\circ}$ de setembro de 2010 , que regulamenta a profissão de Tradutor e Intérprete de Libras-Português. Embora inúmeras críticas possam ser direcionadas ao conteúdo da lei, principalmente o fato de não contemplar a formação em nível de graduação, não podemos desconsiderar que ela é mais um instrumento legal que contribui para retirar da informalidade o trabalho de tradução e da interpretação.

É possível dizer que até o presente momento tivemos alguns avanços nas pesquisas sobre a tradução e a interpretação, bem como, na formação acadêmica do TILSP. Em uma perspectiva histórica, pode-se dizer que, somente no início do século XXI algumas universidades tiveram a iniciativa de oferecer o curso de formação de TILSP em nível superior. Segundo Lacerda (2012, p. 273), “[...] os primeiros cursos de formação específica no Brasil começam a surgir em 2004/2005 por iniciativa de algumas universidades (UNIMEP/SP, Estácio de Sá/RJ, PUC/MG) [...]”. No entanto, a consolidação dessa formação se deu em 2008, com a

SOUZA. O deslocamento da legitimidade dos Tradutores e dos Intérpretes de Libras-Português e o imaginário sociodiscursivo: problematizando o ethos

Belas Infiéis, v. 5, n. 1, p. 39-57, 2016. 
criação do curso de bacharelado em Letras Libras, oferecido pela Universidade Federal de Santa Catarina - na modalidade $\mathrm{EaD}$ - em parceria com várias instituições que se tornaram pólos de apoio presencial . Este curso se tornou modelo para a implantação de diversos cursos de formação de TILSP nas universidades federais pelo Brasil, ofertados na modalidade presencial.

O curso de graduação em Letras Libras tem a incumbência de formar os profissionais TILSP para consolidar a prática interpretativa e a tradutória e possibilitar maior reflexão e gerenciamento da interpretação e da tradução.

\subsection{Deslocamento na Pesquisa}

Podemos observar que aos poucos as pesquisas sobre a tradução e a interpretação de Libras-Português ganham forma dentro do cenário acadêmico. Assim sendo, as pesquisas que focalizam os TILSP tiveram um aumento significativo na última década. Pereira (2010) faz um levantamento sobre os estudos em tradução e em interpretação da Libras-Português, concluídos ou em andamento, inscritos em diferentes programas de mestrado e doutorado. Segundo a autora, “ $[\ldots]$ as produções tenham aumentado sensivelmente no período que marca o 44 reconhecimento oficial da Libras (2002) e sua regulamentação (2005) [...]”(PEREIRA, 2010, p. 110). Este aumento nas pesquisas é resultado de uma lacuna existente na reflexão sobre a prática da tradução e da interpretação dos profissionais, o que é muito positivo para o fortalecimento da profissão.

\section{A legitimidade empírico-caritativa}

A legitimidade empírico-caritativa é um conjunto de representações forjadas e disseminadas através dos imaginários sociodiscursivos em relação aos TILSP. Esta legitimidade reúne um conjunto de valores situados em seu contexto sócio-histórico. Neste caso, a profissão assume um viés empírico acompanhado de uma concepção caritativa. Pelo menos três legitimidades assumem o conjunto de representações empírico-caritativo:

a) Legitimidade por Associação - Situada em uma época com pouca possibilidade de formação, os profissionais legitimavam-se por atuarem nas associações de surdos.

b) Legitimidade Caritativa - Nesse modelo, o intérprete se legitima por sua "benevolência" em favor do surdo. Esse tipo de legitimidade foi, ou talvez seja ainda, reforçada por pessoas que acreditam que essa deve ser a função do tradutor ou intérprete.

$\overline{\text { SOUZA. O deslocamento da legitimidade dos Tradutores e dos Intérpretes de Libras-Português e o imaginário }}$ sociodiscursivo: problematizando o ethos

Belas Infiéis, v. 5, n. 1, p. 39-57, 2016. 
c) Legitimidade por filiação - Segundo Charaudeau (2008, p.70), a legitimidade por filiação "se funda na idéia de que o sujeito deve ser "bem nascido"; de que ele obtém sua legitimidade como uma herança dita "natural". Muitos Codasiii foram legitimados como intérpretes por serem filhos de surdos e terem a língua de sinais como L1 ( primeira língua).

\subsection{Legitimidade formativa-profissionalizante}

Esta legitimidade é uma construção recente motivada por alguns fatores dos quais salientamos o reconhecimento da profissão, a formação acadêmica dos profissionais e as políticas educacionais dos surdos. Esta legitimidade reúne um conjunto de valores aceitos atualmente dos quais salientamos:

a) Legitimidade por formação - Essa legitimidade ocorre com mais intensidade, atualmente, sobretudo a partir da criação do bacharelado em Letras Libras, em 2008, pela Universidade Federal de Santa Catarina - UFSC. Os TILSP que buscam formação específica em nível superior na área de tradução, interpretação ou em áreas afins alcançam esse tipo de legitimidade.

b) Legitimidade por instituição - Alcançada por profissionais que atuam em instituições de prestígio, sejam elas educacionais como as universidades ou instituições que possuem trabalho voltado para os surdos, como escolas de referência. Há casos também de profissionais que atuam em instituições televisivas, do poder judiciário etc.

c) Legitimidade por certificação - Consolidada, principalmente, a partir de 2006 com a criação do Exame Nacional de Certificação de Proficiência em Tradução e Interpretação da Libras-Português. Em vários estados brasileiros esta legitimidade também é obtida por aqueles que se submetem a exames de proficiência no Centro de Apoio aos Surdos - CAS.

Por fim, precisamos salientar que as legitimidades não são estáveis, fixas e cristalizadas. Assim, esses vários tipos de legitimidades estão sobrepostos na constituição identitária dos intérpretes e dos tradutores de Libras-Português.

Todas as ideias discutidas até aqui nos permitem compreender alguns acontecimentos que deslocaram a imagem dos TILSP e que possibilitaram a construção de um novo estatuto da profissão. Este novo estatuto inserido na nova legitimidade traz consigo progressos, por um lado, e, por outro, enormes desafios. Apresentaremos a seguir uma problemática ainda não 
solucionada que traz implicações desafiadoras para os profissionais que se encontram em serviço.

\section{A legitimidade formativa-profissionalizante e a Fragmentação do ethos dos TILSP}

O ethos pode ser conceituado como a construção da imagem de si. Os autores mais recentes que discutem esta problemática definem o ethos como a construção da imagem de si que se constitui em dados preexistentes ao discurso (pré-discursivo) e durante o ato de enunciação - ethos discursivo (AMOSSY, 2013; MAINGUENEAU, 2013; CHARAUDEAU, 2008). Souza (2014), apropriando-se deste arcabouço teórico, investigou a construção da imagem dos TILSP por diversos ângulos:

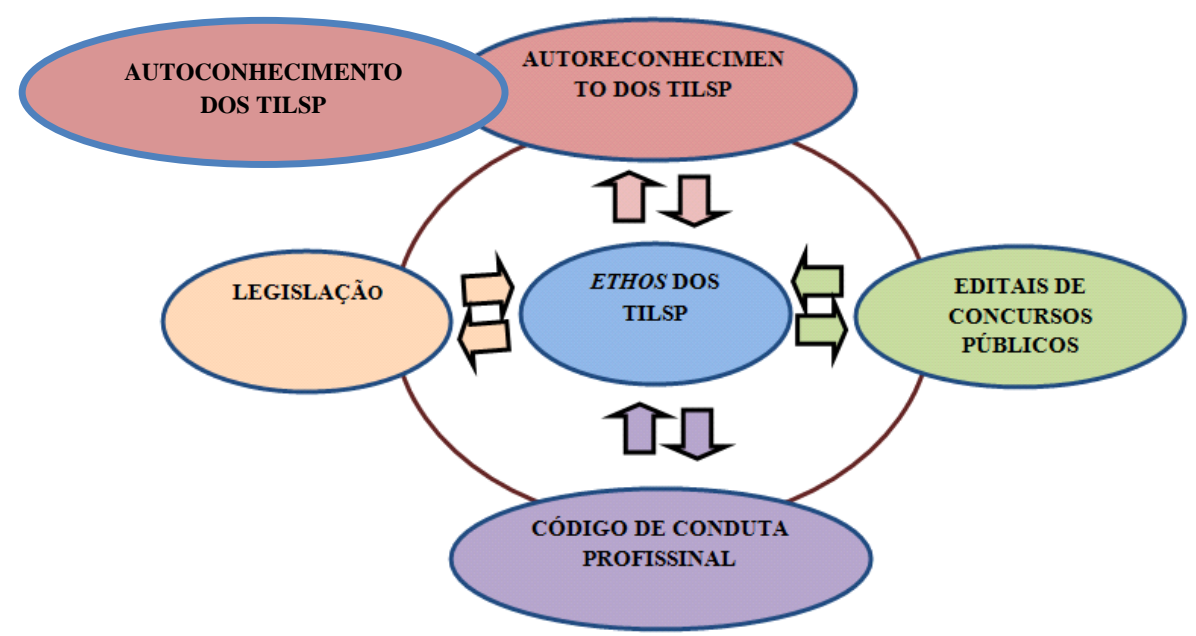

Fonte: SOUZA, 2014

Nesse sentido, o trabalho teve por objetivo analisar a construção do ethos dos TILSP por meio da circulação dos imaginários sociodiscursivos com relação à profissão.

A pesquisa avaliou, em primeiro lugar, as concepções das instituições que contratam os profissionais por meio dos concursos públicos. Posteriormente, observou-se como os códigos de conduta profissional e a legislação caracterizam os TILSP e, de que maneira eles contemplam a complexidade da atuação em múltiplos contextos. Por último, os profissionais foram entrevistados com intuito de verificar o conjunto de representações que estes têm de si mesmos - ethos discursivo. A seguir mostraremos os concursos analisados em instituições situadas no estado do Rio de Janeiro e os documentos reguladores da profissão que foram pesquisados.

SOUZA. O deslocamento da legitimidade dos Tradutores e dos Intérpretes de Libras-Português e o imaginário sociodiscursivo: problematizando o ethos

Belas Infiéis, v. 5, n. 1, p. 39-57, 2016. 


Quadro 1 .
\begin{tabular}{|c|c|}
\hline \multicolumn{2}{|l|}{ Listagem de concursos públicos nas esferas federal e municipal do estado do Rio de } \\
Janeiro \\
\hline Editais & $2008 / 1$ \\
\hline Concurso de Rio das Ostras & $2009 / 2$ \\
\hline Concurso da UFRJ & $2012 / 1$ \\
\hline Concurso de Belford Roxo & $2012 / 2$ \\
\hline Concurso de Nova Iguaçu & $2012 / 2$ \\
\hline Concurso do INES & Anomestre \\
\hline
\end{tabular}

Quadro 2
\begin{tabular}{|c|c|}
\hline \multicolumn{1}{|c|}{ Documentos reguladores da profissão } \\
\hline Etapas & Documentos \\
\hline 1) Legislação & Lei 12.319 de $1^{\circ}$ de setembro de 2010 \\
& (Lei $10.436 / 2002$ e Decreto 5.626/2005 \\
\hline 2) Códigos & Código de ética e código de conduta profissional: FENEIS, APILRJ e \\
& AGILS. \\
\hline 3) Editais & Editais dos concursos públicos com cargos para TILSP. \\
\hline
\end{tabular}

\section{Discussão}

Pelo menos três informações merecem ser problematizadas com relação à profissão: (i) a instabilidade na conceituação de TILSP; (ii) a vinculação dos cargos a outros cargos e (iii) a construção do ethos e as representações institucionais.

\subsection{A instabilidade na conceituação e a construção de diferentes ethos}

Como um dos resultados do estudo de Souza (2014) verificou-se que existe certa instabilidade no conceito de TILSP. Por um lado, os imaginários que circulam nas recentes associações de TILSP definem esse profissional como um sujeito que exerceria suas atividades somente na situação de conferência. Assim sendo, observamos que os documentos não contemplam os diversos contextos em que os profissionais atuam, sobretudo, a área educacional (como abordaremos a seguir, no subitem 3.3). Por outro lado, as instituições que promoveram 
concursos para TILSP também apresentaram instabilidade na nomeação do cargo e nas atribuições da função. Com relação à nomeação do cargo, caracterizou-se o ethos dos TILSP como:
a) ethos de instrutor;
b) ethos de professor;
c) ethos de técnico administrativo.

Por outro lado, conforme a descrição com relação à atribuição do cargo observou-se a construção do ethos oscilando entre:
a) ethos de auxiliar;
b) ethos de conferencista;
c) ethos de mediador.

No decorrer da pesquisa verificamos que a escolha dos nomes dos cargos e as atribuições descritas nos editais não foram acidentais, mas, revestidas por um conjunto de representações 48 que as instituições possuem com relação à profissão. Notou-se no concurso, em que o cargo de TILSP vincula-se ao de instrutor, que a definição da atribuição caracterizava o profissional com o exercício da atividade de apoio. Por outro lado, o concurso em que o cargo estava atrelado à atividade docente, o papel do profissional foi descrito considerando a atividade de mediação, ou seja, como participante do processo de ensino aprendizagem. Por fim, identificamos um descompasso entre a formação exigida nos editais e os níveis de atuação profissional. Assim sendo, observamos que quanto mais alto o nível de atuação dos TILSP menor a formação exigida nos editais. Desse modo, os concursos para o ensino fundamental exigiram, de forma exclusiva ou complementar, a formação em nível superior. Por outro lado, os concursos em que a previsão de atuação dos TILSP é o ensino superior, a formação exigida é apenas o nível médio. 
Quadro 3 - Concursos

\begin{tabular}{|c|c|}
\hline Nova Iguaçu - Fundamental & $\begin{array}{l}\text { Belford Roxo - Concurso II - } \\
\text { Fundamental }\end{array}$ \\
\hline Nome do Cargo & Nome do Cargo \\
\hline $\begin{array}{l}\text { Professor II - Intérprete de Libras - } \\
\text { Profissional Ouvinte }\end{array}$ & Intérprete de Libras \\
\hline Qualificação & Qualificação \\
\hline Médio na modalidade & Ensino Médio completo no magistério ou \\
\hline Magistério/Normal ou Normal Superior ou & Graduação Licenciatura Plena com \\
\hline Pedagogia com habilitação em Educação & licenciatura plena em qualquer área com \\
\hline Infantil e/ou Séries Iniciais do Ensino & Certificação de Proficiência em Tradução e \\
\hline Fundamental e Certificação do Exame & Interpretação $\quad$ de $\quad$ Libras/Língua \\
\hline $\begin{array}{l}\text { Nacional de Proficiência em Libras } \\
\text { reconhecido pelo MEC ou Curso de Libras } \\
\text { reconhecido nelo MEC }\end{array}$ & Portuguesa/Libras reconhecido pelo MEC. \\
\hline
\end{tabular}

\begin{tabular}{|c|c|c|}
\hline $\begin{array}{l}\text { INES - Fundamental, } \\
\text { Médio e Superior }\end{array}$ & UFRJ - Superior & $\begin{array}{l}\text { Rio das } \\
\text { Ostras - } \\
\text { Concurso I }- \text { Nível } \\
\text { Fundamental }\end{array}$ \\
\hline Nome do Cargo & Nome do Cargo & Nome do Cargo \\
\hline $\begin{array}{l}\text { Tradutor e Intérprete de } \\
\text { Língua Brasileira de Sinais } \\
\text { - LIBRAS }\end{array}$ & $\begin{array}{l}\text { Tradutor Intérprete de } \\
\text { Libras. }\end{array}$ & $\begin{array}{l}\text { Instrutor de Língua } \\
\text { Brasileira de Sinais II }\end{array}$ \\
\hline Qualificação & Qualificação & Qualificação \\
\hline 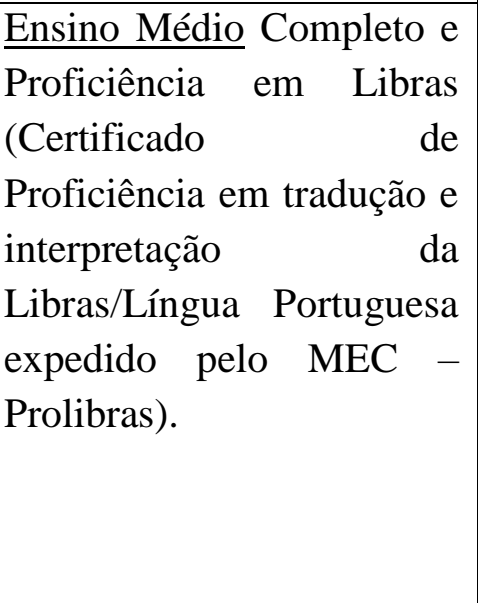 & $\begin{array}{l}\text { Ensino Médio completo } \\
\text { profissionalizante na área; } \\
\text { OU Ensino Médio } \\
\text { Completo e } \underline{\text { Curso Técnico }} \\
\text { na área }\end{array}$ & $\begin{array}{l}\text { Curso Superior Completo } \\
\text { em qualquer Área + Curso } \\
\text { de Libras em Instituição } \\
\text { competente com carga } \\
\text { horária mínima de } 150 \\
\text { horas ou Certificação no } \\
\text { Exame Nacional de } \\
\text { Proficiência em Libras } \\
\text { expedido pelo MEC } \\
\text { (Ministério de Educação e } \\
\text { Cultura }\end{array}$ \\
\hline
\end{tabular}

SOUZA. O deslocamento da legitimidade dos Tradutores e dos Intérpretes de Libras-Português e o imaginário sociodiscursivo: problematizando o ethos

Belas Infiéis, v. 5, n. 1, p. 39-57, 2016. 


\subsection{Cargo de TILSP, específico ou atrelado?}

A prática comum para algumas instituições que contratam TILSP consiste em promover este cargo baseando-se em outros. Neste caso, a escolha será norteada em consonância com as concepções que a instituição tem da profissão.

Quando o cargo é específico para o TILSP, as principais vantagens identificadas consistem na construção do papel político da profissão por meio de uma atribuição adequada à atuação profissional. Acreditamos ser esse o ethos evocado pela ampla maioria dos profissionais. Entretanto, este ainda não parece ser o caso mais frequente. Os imaginários em relação à profissão variam e, de fato, isso contribui para que o ethos dos TILSP circule de forma fragmentada.

Quando o cargo de TILSP é vinculado a outro, corre-se o risco de que a escolha deste seja orientada para categorias profissionais que não tenham nenhuma relação ou semelhança com a função. Por outro lado, pode-se também estar vinculado a profissões que, por certa semelhança, possibilite indiretamente a constituição política dos TILSP. A desvantagem do cargo específico em alguns concursos consiste no pequeno número de profissionais contratados

50 nas diversas instituições que, se comparado com outras categorias, ficam em quantidades diminutas. De fato, na maioria dos casos, as vagas são consideradas insuficientes para formar a massa necessária para lutar por melhorias profissionais e alcançar a visibilidade das instituições.

Há alguns desdobramentos com relação ao cargo específico, sobretudo quando falamos de sindicalização. Desse modo, quando o cargo de TILSP está vinculado a outro cargo, incorporam-se também as conquistas geradas por estes. Parece o caso do TILSP vinculados ao cargo de professor - fato ocorrido no concurso para o município de Nova Iguaçu - pois, estes gozam das conquistas auferidas pela classe desses profissionais ao longo dos anos. Desse modo, o TILSP pode se integrar ao sindicato docente e, sobretudo, usufruir das conquistas dos profissionais da área da educação.

A vinculação de uma profissão a outra não é o mais desejável para nenhuma categoria profissional. Desta forma, os profissionais devem aos poucos almejar a emancipação e autonomia do seu cargo. No entanto, há que se dizer, sobretudo na atual conjuntura, que existem benefícios e limitações na vinculação do cargo que devem ser problematizados. Obviamente, o ponto mais frágil desta vinculação reside na (con)fusão da atribuição profissional.

Portanto, identificamos que os cargos disponibilizados nos concursos analisados não são cargos específicos. Assim sendo, na esfera federal verificou-se a vinculação ao cargo de

SOUZA. O deslocamento da legitimidade dos Tradutores e dos Intérpretes de Libras-Português e o imaginário sociodiscursivo: problematizando o ethos

Belas Infiéis, v. 5, n. 1, p. 39-57, 2016. 
técnico administrativo. Nos municípios, a vinculação ocorreu relacionada à docência e aos instrutores (no município de Rio das Ostras).

Diante das considerações, podemos entender que atualmente o cargo de TILSP encontra-se em maior parte vinculado a outros. Na próxima seção, continuaremos nossa análise com base no código de conduta profissional.

\subsection{A construção do ethos: análise do código de conduta profissional}

Escolhemos três códigos de conduta profissional para nossa análise. Em relação à definição dos TILSP, encontramos as informações abaixo:

Quadro 5
\begin{tabular}{|c|c|}
\hline Instituição & Definição do TILSP \\
\hline FENEIS & Não define explicitamente \\
\hline APILRJ & Não define explicitamente \\
\hline AGILS & $\begin{array}{r}\text { Tradutor e Intérprete de Línguas de Sinais: profissional que traduz e } \\
\text { interpreta a língua de sinais para a língua falada e vice-versa em } \\
\text { quaisquer modalidades que se apresentar (oral ou escrita). }\end{array}$ \\
\hline
\end{tabular}

Escolhemos fazer uma análise da materialidade linguística dos códigos de conduta profissional mais recente. Almejamos fazer este teste porque não identificamos, a priori, em quais situações o documento se aplica. Foi possível identificar algumas palavras que se repetem durante todo o texto.

Quadro 6

\begin{tabular}{|c|c|}
\hline \multicolumn{2}{|c|}{ APILRJ } \\
\hline Palavras & Ocorrência \\
\hline Clientes/cliente & 16 vezes \\
\hline Serviço & 22 vezes \\
\hline
\end{tabular}

Quadro 7

\begin{tabular}{|c|c|}
\hline \multicolumn{2}{|c|}{ AGILS } \\
\hline Palavras & Ocorrência \\
\hline Clientes/cliente & 9 vezes \\
\hline Serviço & 5 vezes \\
\hline
\end{tabular}

SOUZA. O deslocamento da legitimidade dos Tradutores e dos Intérpretes de Libras-Português e o imaginário sociodiscursivo: problematizando o ethos

Belas Infiéis, v. 5, n. 1, p. 39-57, 2016. 
Isso nos faz supor que os códigos prevêem uma relação comercial e de prestação de serviços. Procuramos também identificar amostragem linguística que se relacionassem com o ambiente educacional (por ser esta o maior campo de atuação). Buscamos nos dois códigos as seguintes palavras:

Quadro 8
\begin{tabular}{|c|c|}
\hline Palavras & Ocorrência \\
\hline Aluno & 0 \\
\hline Professor & 0 \\
\hline Escola & 0 \\
\hline Ensino & 0 \\
\hline
\end{tabular}

Os códigos de conduta profissional prezam muito pela impessoalidade. Isso é algo que não está de acordo com o contrato didático. No contexto educacional, regido por um contrato comunicativo dialogaliv $^{\text {iv }}$, todos os parceiros estão presentes fisicamente, estão próximos e o aspecto relacional assume um papel fundamental, pois, ao contrário de outros cenários de 52 atuação (por exemplo, em situação monologal), no ambiente educacional há um contato diário com o público alvo da interpretação. Logo, este relacionamento constante evoca um contrato específico que integra o processo de ensino aprendizagem.

Desse modo, pode-se dizer que o documento não contempla os TILSP em todas as áreas de atuação e não contempla toda complexidade que envolve as diversas situações de comunicação em que os profissionais estão envolvidos.

\section{A construção do ethos discursivo}

Para analisar o ethos discursivo tivemos o cuidado de entrevistar profissionais TILSP engajados com a profissão e com vasta experiência na área. O objetivo foi de reunir as vozes e refletir sobre os imaginários sociodiscursivos que circulam entre os profissionais. Apresentaremos a fala de três entrevistados.

Todos os TILSP entrevistados são graduados e atuam nas áreas educacionais e de conferências. No entanto, um desses profissionais dedica-se, atualmente, apenas ao contexto de conferências. Nesta perspectiva, os profissionais entrevistados possuem formação em nível de graduação em cursos distintos. O entrevistado M é formado em Letras - Espanhol e atua há muitos anos como TILSP. Passou por várias instituições de surdos como profissional. Os 
sujeitos $\mathrm{N}$ e C são formados em Bacharelado em Letras Libras e também são considerados referências na área da tradução e da interpretação.

Este é um recorte de pesquisas que realizamos com profissionais TILSP experientes envolvendo 10 questões relacionadas à doxa institucional (conjunto de representações que as instituições constroem com relação à profissão) e o ethos discursivo (como os profissionais se constroem discursivamente). Apresentaremos apenas partes das entrevistas.

Quadro 9

1 - Como você avaliaria a situação profissional dos TILSP atualmente?

\begin{tabular}{|r|l|}
\hline $\mathbf{N}$ & $\begin{array}{l}\text { Em ascensão. Tal profissão está em construção e vem ganhando seus status como } \\
\text { ofício recentemente. Ainda há muita precariedade no Brasil no que tange esses } \\
\text { profissionais, seja por fatores externos (visão social) ou internos (dos próprios } \\
\text { TILSP). }\end{array}$ \\
\hline $\mathbf{C}$ & $\begin{array}{l}\text { Estamos no momento pontual e significativo e ao mesmo tempo de tensão e } \\
\text { necessidade de busca de articulação e aproximação enquanto categoria } \\
\text { profissional dos profissionais TILS. Visto que somente nos últimos } 5 \text { anos } \\
\text { ampliou-se, mas significativamente, os cursos de formação em ensino superior } \\
\text { na área de tradução e interpretação. Apenas a partir de 2008, no Rio de Janeiro, } \\
\text { iniciaram os processos seletivos de concurso público para efetivar os TILS. }\end{array}$
\end{tabular}

Os discursos dos profissionais entrevistados apresentaram um consenso em relação a melhorias em alguns aspectos da profissão. Entretanto, logo a seguir observaremos inúmeros problemas existentes e os problemas gerados pela falta de compreensão das instituições e dos profissionais sobre a complexidade do processo de tradução e de interpretação e os limites de atuação.

SOUZA. O deslocamento da legitimidade dos Tradutores e dos Intérpretes de Libras-Português e o imaginário sociodiscursivo: problematizando o ethos

Belas Infiéis, v. 5, n. 1, p. 39-57, 2016. 
2 - Como você acha que as instituições que contratam os TILSP, sejam elas públicas ou privadas, visualizam a profissão?

N Como um APOIO aos surdos. As empresas deixam seus banheiros acessiveis, colocam sinais luminosos, rebaixam as bancadas e contratam intérpretes. Simples assim.

$\mathbf{M}$ Algumas ainda tem a visão de que os intérpretes de LIBRAS são ora tutores dos surdos, ora pessoas generosas trabalhando com solidariedade, outras já compreendem sua atuação como um profissional de fato.

C Visualizam os TILS, até hoje, como trabalhadores da categoria técnica exercendo apenas trabalhos "braçais, mecânicos, robóticos". Não compreendem a complexidade das exigências além das físicas, linguísticas e tradutórias. Da necessidade de competência referencial (formação e conhecimentos em geral). E os complexos processos de elaboração mental para compreensão e adaptações linguísticas, culturais, semânticas e pragmáticas necessárias para embasar as escolhas tradutórias realizadas na tradução e interpretação.

Fonte: Souza (2014)

Tecendo as considerações, podemos avaliar que os imaginários sociodiscursivos das instituições com relação aos TILSP, não correspondem ao modo como estes se visualizam. No entanto, o ethos dos profissionais tem sido construído, em parte pelas concepções que as instituições fazem deles, pois elas detêm o poder de disponibilização do cargo. Assim, as atribuições dos TILSP são elaboradas em consonância com o conjunto de representações que a instituição tem do profissional. Este fato contribui para fragmentar o ethos coletivo, pois, a instância institucional tem a legitimidade de promover o cargo conforme seu próprio imaginário. É desta forma que as instituições promovem as contratações e desconsideram, em parte, o estatuto ligado ao ethos discursivo dos profissionais. 


\section{Considerações finais}

Este trabalho é fruto de pesquisa que tem como foco analisar os imaginários sociodiscursivos que circulam com relação aos TILSP. O estudo evidencia que o momento atual tem sido marcado por um deslocamento na legitimidade do profissional. Com relação à construção do ethos dos TILSP, observou-se que esta não depende somente dos próprios profissionais, mas, principalmente, das instituições que promovem os concursos e dos documentos oficiais. Notou-se que cada instituição constrói o cargo de TILSP de acordo com suas necessidades e com base em sua própria representação institucional da profissão. Isso significa dizer que o ethos dos TILSP é fragmentado pelas instituições, pois estas acomodam o cargo de acordo com suas próprias necessidades, violando, em alguns casos, à natureza da atividade de interpretação ou de tradução.

No caso dos documentos oficiais, pode-se dizer, em relação à legislação, que esta não tem acompanhado o avanço acadêmico que os TILSP vivenciam atualmente. Diante dos concursos com cargos de nível médio - formação exigida pela Lei 12.319/10 - o efeito negativo que isso pode gerar é possibilidade da profissão ser aspirada apenas em início de carreira pelos profissionais e, à medida que se obtém formação mais sólida, ocasionar uma migração para outras áreas com maior valorização.

Os códigos de conduta profissional contemplam a atuação dos TILSP em contexto de conferência, todavia, deixam a desejar nas demais áreas de atuação. É prudente que haja um aperfeiçoamento desses códigos nos próximos anos.

Em um futuro próximo, às pesquisas podem demonstrar como os TILSP, adentrando os espaços institucionais recentemente, acomodarão seu ethos e de que maneira as instituições, agora com mais contatos com esses profissionais, reformularão seus imaginários sociodiscursivos.

\section{REFERÊNCIAS BIBLIOGRÁFICAS}

AMOSSY, Ruth (Orgs.). Imagens de si no discurso: A construção do ethos. $2^{\text {a }}$ São Paulo: Contexto: 2013.

BRASIL, Decreto 5.625 de 22 de dezembro de 2005.

BRASIL, Lei 10.436 de 24 de abril de 2002.

BRASIL, Lei 12.319 de $1^{0}$ de setembro de 2010 .

SOUZA. O deslocamento da legitimidade dos Tradutores e dos Intérpretes de Libras-Português e o imaginário sociodiscursivo: problematizando o ethos

Belas Infiéis, v. 5, n. 1, p. 39-57, 2016. 
CHARAUDEAU, P. Linguagem e Discurso: modos de enunciação. $2^{\mathrm{a}}$ ed. São Paulo: Contexto, 2010.

CHARAUDEAU, P. Discurso Político: modos de enunciação. São Paulo: Contexto, 2008. CORREAA, Angela Maria da Silva: Uma abordagem discursiva da tradução. RECORTE, 2007.

LACERDA, Cristina B. Feitosa. O intérprete de língua de sinais (ILS). In: Ana Claudia Lodi; Ana Cláudia. B; Mélo, Ana D. B. de; Fernandes, E. (Orgs.). Letramento, bilinguismo e educação de surdos - Porto Alegre: Editora Mediação, 2012.

LEITE, E.M.C. Os papéis do intérprete de libras na sala de aula inclusiva. Petrópolis - RJ: Arara Azul, 2005.

MAINGUENEAU, Dominique. Ethos, cenografia, incorporação. In: AMOSSY, Ruth (Org.). Imagens de si no discurso: a construção do ethos. São Paulo: Contexto, 2013.

PEREIRA, M.C.P. Produções acadêmicas sobre Interpretação de Língua de Sinais: dissertações e teses como vestígios históricos. In: QUADROS, R.M (Org.). Cadernos de Tradução. Santa Catarina: PGET, 2010/2. p. 99-117.

56 QUADROS, R.M: O Tradutor e Intérprete de Língua Brasileira de Sinais e Língua Portuguesa. Secretaria de Educação Especial; Programa Nacional de Apoio à Educação de Surdos - Brasília: MEC; SEESP, 2004.

SANTOS, S. A. Intérpretes de Língua de Sinais: um estudo sobre as identidades. Dissertação de Mestrado: Universidade Federal de Santa Catarina, 2006.

SOUZA, L.C.S. A Construção do Ethos dos Tradutores e Intérpretes de Língua Brasileira de Sinais e Português: concepções sobre a profissão. Dissertação de Mestrado: Universidade Federal do Rio de Janeiro, 2014.

. A Atuação do Tradutor e Intérprete de LIBRAS/Português em situação dialogal: uma proposta de representação esquemática da situação de interpretação.In: CONGRESSO BRASILEIRO DE LINGUÍSTICA APLICADA, v.2, n.1, Rio de Janeiro, 2013. Anais eletrônicos. Rio de Janeiro: Associação Brasileira de Linguística Aplicada.

\footnotetext{
${ }^{\text {i }}$ Luiz Cláudio da Silva SOUZA - É professor do curso Letras Libras - Tradução da Universidade Federal de Goiás e coordenador da equipe de intérpretes de Libras-Português da mesma universidade. Doutorando no Programa Interdisciplinar em Linguística Aplicada pela Universidade Federal do Rio de Janeiro. Mestre pelo Programa Interdisciplinar em Linguística Aplicada pela Universidade Federal do Rio de Janeiro (2014). Licenciado em Química pela Universidade do Grande Rio (2008). Disponível em: http://lattes.cnpq.br/4696207472395354. Acesso: junho 2016.

ii Compreendemos que a atividade tradutóra e a interpretativa são operacionalizadas de formas distintas. No entanto, neste artigo não temos a pretensão de descrever esta diferenciação. Assim sendo, este trabalho tem como principal objetivo apresentar o deslocamento da legitimidade e a construção da imagem dos TILSP.

iii Coda - Children of Deaf Adults (Filhos de Pais Surdos).
}

SOUZA. O deslocamento da legitimidade dos Tradutores e dos Intérpretes de Libras-Português e o imaginário sociodiscursivo: problematizando o ethos

Belas Infiéis, v. 5, n. 1, p. 39-57, 2016. 
iv Em situação dialogal, os parceiros da comunicação estão presentes fisicamente, o contrato permite troca e o ambiente físico é perceptível pelos dois parceiros. Ao contrário, em situação monologal os parceiros não estão presentes fisicamente, o contrato não permite troca e o ambiente não é perceptível aos dois parceiros (CHARAUDEAU, 2010). A situação monologal ocorre, por exemplo, quando se traduz um texto em português para a Libras por meio de gravação em vídeo.

RECEBIDO EM: 07 de março de 2016

ACEITO EM: 20 de junho de 2016 